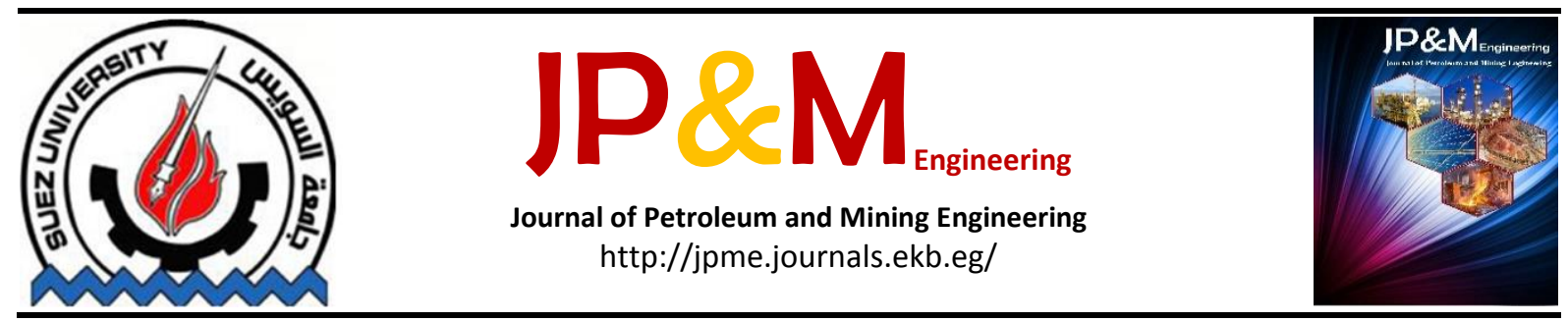

\title{
Mixed Refrigeration Process for Improving NGL Recovery of El-Wastani Gas Plant
}

\author{
Ashour A. Ibrahim ${ }^{a}{ }^{*}$, Walaa M. Shehata ${ }^{b}$, Fatma K. Gad ${ }^{b}$ \\ ${ }^{a}$ El Wastani Petroleum Company- Egypt.

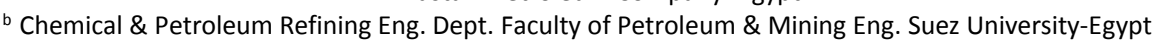

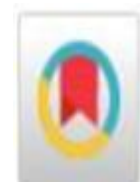

\section{Keywords}

Mixed refrigerant; NGL recovery; gas processing.

\begin{abstract}
Gas processing for natural gas liquids (NGLs) and liquefied petroleum gas ( LPG) recovery is becoming of great interest due to higher sale prices of these products as well as the increase in market demand. However, many of the present recovery units in operation are not giving the desired revenue. The main focuses this study is to retrofit an Egyptian LPG plant for improving NGL recovery. A comparison had been hold between the most applicable cryogenic techniques -in which this plant could be retrofitted to- which can achieve the same targeted cooling and recovery in terms of power consumption and required additional capital cost to detect the best techniques to be applied to maximize NGL liquid Recovery. The replacement of pure propane refrigerant used to $\mathrm{C}_{5}{ }^{+}$recovery by a mixed refrigerant type was selected as the best techniques which can be applied to improve NGL recovery. Due to its proper physical and thermodynamic properties that lower exergy losses and raise the exchanger effectiveness. Another comparison had been hold to detect which degree of recovery (butane or propane) will be selected for retrofitting the plant and giving

the highest return on investment.
\end{abstract}

\section{Introduction}

Natural gas liquids (NGLs), are valuable products derived from the processing of natural gas and refining of crude oil. Five major NGLs - ethane, propane, butane, iso-butane, and natural gasoline are used by petrochemical companies as feed stocks and by refineries as blending and processing components[1].

Recovery of NGL components in gas not only may be required for hydrocarbon dew point control in a Natural gas stream, but also yields a source of revenue, as NGLs normally have significantly greater value as separate marketable products. NGL separation from natural gas stream results in a phase change. In practice, the use of energy separating agent (ESA) and mass separating agent (MSA) are the main two distinctive options. Removing heat by refrigeration will allow heavier components to condense; hence, a liquid phase is formed. While to separate NGL in MSA, a new phase is developed by using either a liquid in contact with the gas (absorption) or a solid material in contact with the gas stream (adsorption). The membranes is used as a new technology as a MSA to separate the two phase streams (gas and hydrocarbon liquids after condensation) [11].

The process retrofit can dramatically improve the economics of an existing plant by reducing the unit operating cost and boosting product revenues. Retrofitting the existing plants to a more efficient process can provide the following benefits [12].

- Efficiency increase, which result in a reduction in the energy consumption per unit of gas processed.

- Increased plant throughput with the same gas compression power. This will reduce the fixed costs per unit of gas processed.

- An increase in plant throughput translates into greater product sales and revenue.

- $\quad$ An increase in liquid recovery efficiency, and hence, raising product sales and revenue.

\section{Case study}

The case study presented is El-Wastani petroleum LPG/NGLs recovery plant located at Egypt. This plant operates wells network in order to process the feed gas stream to deliver sales gas, stabilized condensate 
and liquefied petroleum gas (LPG) via central processing facilities (CPF) plant.

This plant is structured around the following two fundamental principles:

- $\quad$ Stage-I: to ensure early gas production (160 MMSCFD) and condensate stabilization.

- $\quad$ Stage-II: To utilize a deep-cut design that allows separation of components from the inlet feed to produce an LPG product.

Referring to the simplified block diagram in Figure (1), and the above two principles in addition to the combined incoming feed, gas streams from El Wastani wells are routed to inlet separators, gas from separators goes through mechanical refrigeration unit (MRU-I) which uses propane as a pure refrigerant to exchange heat with the inlet gas to decrease its temperature to $-10 \stackrel{\circ}{ } \mathrm{C}$. The unit controls sales gas quality and also recovers additional hydrocarbon liquids.

The condensate liquid, which has been come from the feed gas group separators is sent to the condensate stabilization unit (CSU) and also hydrocarbon liquids from MRU-I can either be sent to the CSU (stage-I operation) or to the De-Ethanizer tower (Stage-II operation).

Gas from the MRU-I can either goes to stage-I to be compressed or to stage-II, to be dried in the molecular sieves dehydration unit (MSU). For further chilling of the dried gas, it is cooled across a cryogenic heat exchanger called as cold box. Consequently, it is sent to turbo expander unit for more recovery of hydrocarbon liquids. The cold gas is also used to cool dried gas coming into the cold box.

Hydrocarbon liquids from the MRU-I and turboexpander units are fed to the De-Ethanizer tower. The ethane free De-Ethanizer bottom liquid goes to the De-Butanizer tower where the LPG is recovered as the top product of De-Butanizer tower. Liquid bottom from the De-Butanizer tower is sent to CSU and recovered as condensate product with the stabilizer tower bottom also to recover more butane from this stream [3].

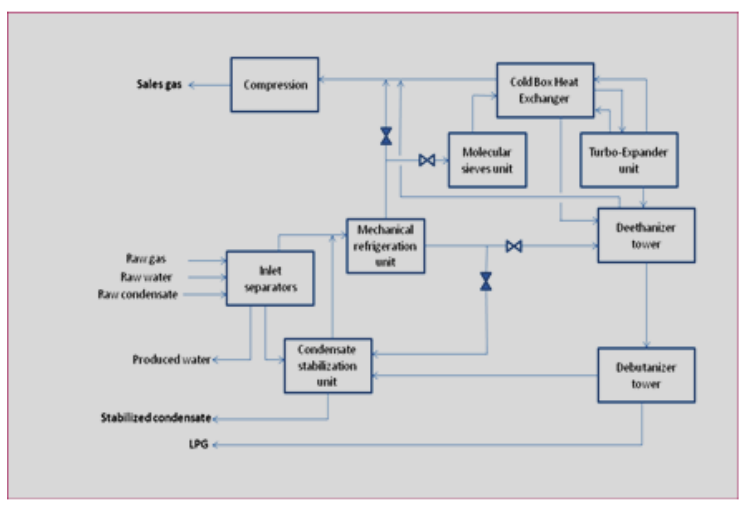

Figure 1 Central Processing Facilities Block Diagram

\section{Design/retrofit basis}

The LPG/NGLs recover plant presented was originally designed to process $160 \mathrm{MMscfd}$ of feed gas and $4000 \mathrm{bbl} /$ day as raw condensate, to produce 228 ton/day of LPG product -with $80 \%$ of butane recovery and $35 \%$ of propane recovery- to the local market, $5000 \mathrm{bbl} /$ day stabilized condensate and 156.4 MMscfd sales gas to the Egyptian national gas grid (N.G.G.), with composition analysis shown in Table (1). The plant is retrofitted to two alternatives; retrofitting the plant for maximizing LPG recovery, and retrofitting the plant for maximizing propane recovery.

Retrofitting the plant for maximizing LPG recovery is limited to the above original design basis in addition to the original design power consumed by MRU-I compressor (1265 hp) to improve both butane and propane recovery percent up to $95 \%$ \& $50 \%$ for each component respectively.

Retrofitting the plant for maximizing propane recovery is limited to the above original design basis also, in addition to propane recovery up to $93 \%$ which is limited by Mono ethylene glycol (MEG) operating temperature (above $-48 \mathrm{C}$ ).

\section{Methodology}

The simulation package used in this study is HYSYS 8.8 which is based on Peng-Robinson equation of state for calculations. This study aims at retrofitting of LPG plant for improving NGL recovery via selecting mixed refrigerant for cooling process. This plant is retrofitted to one of two suggested retrofitting models; retrofitting the plant to increase the LPG recovery-in which the butane and propane recovery percent will be increased from $80 \%$ and $35 \%$ as per design case up to $95 \%$ and $50 \%$ respectively, retrofitting the plant to produce propane as a pure product beside the LPG-in which propane recovery percent was increased from $35 \%$ as per design case up to $93 \%$. To achieve this retrofit the following steps were proceeded:

A comparison had been held between the most applicable cryogenic techniques -in which this plant could be retrofitted to- which can achieve the same targeted cooling and NGL recovery in terms of power consumption and required additional capital cost. Comparison will be between increasing Turboexpander horse power, increasing propane refrigeration horse power and replacing propane refrigerant by mixed refrigerant.

Selecting and optimizing the mixed refrigerant composition which can achieve the highest cooling effect for both suggested retrofitted models (increasing LPG recovery or propane recovery) taking into consideration Alfeev et al. guidelines [4].

Studying the performance of the plant after replacing the propane refrigerant by mixed type in retrofitting this existing plant to increase LPG recovery percent on energy consumption, meanwhile the feed composition, feed figures, refrigeration, TE \& sales gas compression horsepower and product spec kept constant as design case. All percentage recoveries reported shall be calculated as presented in Eq. (1). 
Percentage recovery

Component mass flow in LPG \& condensate product

$=(\overline{\text { Component mass flow in the total feed to the inlet separator }}$

- Studying the performance of the plant after replacing the propane refrigerant by other mixed type to increase propane recovery in the second retrofitted model on energy consumption, meanwhile the feed composition, feed figures, TE \& sales gas compression horsepower and product spec kept constant as design case. In this step refrigeration horsepower isn't limited to design case to can deep cool the feed gas and increase propane recovery; propane can be produced as final product with percentage described in Eq. (2).

Percentage recovery

$=($ Component mass flow in LPG, Propane \& condensate product $=($ Component mass flow in the total feed to the inlet separator $)$

(2)

- $\quad$ Rating the existing facilities for the two suggested retrofitting models and check if it can handle the additional required functions, and if not determine the additional required equipment and perform the cost estimation based on return on investment (ROI).

\section{Process Equipment Rating and sizing}

The existing process equipment had been rated according to design data sheet for new functions and checked if it can fit for new requirements, using Aspen HYSYS 8-8 simulation program (Design rigorous and rating tools) \& Dresser Rand program for gas compressors simulation, and this modeling will be helpful in bottlenecking the existing process equipment to get the required process design data needed for the preliminary study of the retrofitted plant and also will be used to get estimated purchasing cost for the new process equipment.

The new added equipment will be sized, by using Aspen HYSYS simulation program (Sizing tool) to get the proper specification of the concerned equipment and roughly estimation for required capital cost.

\section{Cost/profitability Estimation}

The determination of optimum retrofit (LPG or Propane recovery mode) to operate plant under study with a new modifications and maximizing the profitability is based on the highest return on investment (ROI) principle.

The calculations of $R O I$ as described in Eq. (3) are mainly consisting of two major terms; the net profit which is resulting via productivity increases as a result from retrofit modification; the total capital investment which includes the cost of purchased equipment, installation and foundation, instrumentation, piping, and commissioning works.

$$
\text { ROI }=\frac{\text { Net Profit }}{\text { Total capital investement }}
$$

The total capital investment includes the fixed capital cost in addition to the working capital cost. Pay-back period is the period of time required for the return on an investment to "repay" the sum of the original investment, Pay-back period can be calculated as presented in Eq. (4).

Pay - back period $=1 /$ ROI
Table 1 Inlet Gas and Liquid Analysis

\begin{tabular}{|c|c|c|}
\hline \multirow{2}{*}{ Component } & \multicolumn{2}{|c|}{ Mole \% } \\
\hline & Gas & Liquid \\
\hline N2 & 0.04 & 0.00 \\
\hline $\mathrm{CO} 2$ & 0.32 & 0.05 \\
\hline C1 & 86.99 & 3.72 \\
\hline $\mathrm{C} 2$ & 7.46 & 2.29 \\
\hline C3 & 2.72 & 2.09 \\
\hline $\mathrm{i}-\mathrm{C} 4$ & 0.81 & 2.57 \\
\hline$n-C 4$ & 0.62 & 3.46 \\
\hline $\mathrm{i}-\mathrm{C} 5$ & 0.30 & 5.12 \\
\hline$n-C 5$ & 0.17 & 3.71 \\
\hline C6 & 0.19 & 10.47 \\
\hline $\mathrm{C} 7$ & 0.13 & 16.21 \\
\hline $\mathrm{C} 8$ & 0.06 & 19.72 \\
\hline C9 & 0.01 & 11.31 \\
\hline $\mathrm{C} 10$ & 0.00 & 6.80 \\
\hline C11 & 0.00 & 3.83 \\
\hline $\mathrm{C} 12$ & 0.00 & 2.57 \\
\hline C13 & 0.00 & 1.92 \\
\hline $\mathrm{C} 14$ & 0.00 & 1.27 \\
\hline $\mathrm{C} 15$ & 0.00 & 1.16 \\
\hline $\mathrm{C} 16$ & 0.00 & 0.58 \\
\hline $\mathrm{C} 17$ & 0.00 & 0.56 \\
\hline C18 & 0.00 & 0.30 \\
\hline C19 & 0.00 & 0.10 \\
\hline $\mathrm{C} 20$ & 0.00 & 0.07 \\
\hline $\mathrm{C} 21$ & 0.00 & 0.05 \\
\hline $\mathrm{C} 22$ & 0.00 & 0.03 \\
\hline $\mathrm{C} 23$ & 0.00 & 0.04 \\
\hline $\mathrm{H} 2 \mathrm{O}$ & 0.18 & 0.00 \\
\hline TOTAL & 100.00 & 100.00 \\
\hline Mole weight & 19.13 & 107.2 \\
\hline
\end{tabular}

\section{Results and Discussion}

\section{Retrofitting the plant for maximizing LPG recovery}

To improve LPG recovery, numerous techniques had been established, but due to applying refrigerated Turbo-expansion process technique to El-Wastani plant, retrofitting could be applied to one of applied technique sections as following:

- Upgrading mechanical refrigeration package

- Upgrading Turbo-Expansion Process

- Mixed refrigeration

As shown from Figure 1, well head streams are physically separated, separated condensate is further stabilized to storage and pipeline specification, separated gas is further cooling on two stages; the 1st one by mechanical refrigeration unit using propane refrigerant to condense saturated $\mathrm{C} 5+$ which is further fractionated through De-Ethanizer tower and the remaining gas is dehydrated by molecular sieve package prior to the second stage of cooing using 
Turbo-expansion process to condense feed stock of fractionators De-Ethanizer and De-Butanizer and the remaining gas with pipeline spec is compressed to national gas grid, LPG is produced through fractionation package with storage and pipeline spec to (Petroleum Pipeline Company) PPC Grid.

To decide which technique will be further studied in detail to improve propane and butane recovery, three HYSYS models (Figures 2, 3 \& 10) had been built for the three proposed techniques on the same degree of cooling and butane recovery (above $95 \%$ ) and the design basis mentioned above, models results are summarized and tabulated below.

\section{Upgrading mechanical refrigeration package technique}

Upgrading mechanical refrigeration package technique require high fixed capital investment compared to the other techniques, see Figure (2) and this may be excused by low exchanger effectiveness and high exergy loss for pure refrigerant cycles which require higher capacities equipment.

\section{Upgrading Turbo Expansion (TE) package technique}

Upgrading Turbo Expansion (TE) package technique require higher operating cost compared to the other techniques, see Figure ( 3 ) and this excused by sales gas lower efficiency at high compression ratio (Figure (4)).

\section{Mixed refrigerant technique}

Mixed refrigerant selection for LPG retrofitted plant

According to HYSYS models result which had been built to differentiate between the pure and mixed refrigerants on theoretical basis-Figures (5) \& (6) and Table (2), found the following:

Mixed refrigerant exhibit very close cooling curves; the minimum temperature approach occurs at any point across heat exchanger length but the minimum temperature approach occurs at one end of the heat exchanger and become greater at the second for pure refrigerant.

The pure refrigerant propane evaporates at constant temperature but the mixed one evaporates on a wide range of temperature.

Mixed refrigerant exhibit lower Exergy, higher coefficient of performance (COP) and higher exchanger effectiveness (Ex. Eff.), hence mixed refrigerant is favoured for using for refrigeration units.

Different mixed refrigerant compositions had been performed to select the optimum composition, which achieves the highest cooling effect, minimum temperature approach $\Delta \mathrm{T}$ and the aimed cooling temperature at the same consumed horse power (1265 hp) used by pure propane refrigerant in the original design case, results were tabulated in Table (3) and MR-04 was selected as the composition base for LPG recovery mode as shown in Table (4).

As shown from Tables (3) and (4) and Figures (7) and (8) above;
MR-04 and MR-02 achieve the highest cooling effect

Although MR-02 can achieve the highest cooling effect, but it can't achieve the required cooling temperature, as a result of high evaporating temperature at the end of evaporation $\left(6^{\circ} \mathrm{C}\right)$.

MR-04 is selected as a base composition for LPG recovery mode.

Mixed refrigerant technique exhibit the lowest operating and capital cost (see table 5 and figure 9), as a result of mixed refrigerant physical and thermo dynamical properties led to higher exchanger effectiveness, COP and lower exergy loss and hence it is decided to retrofit the existing LPG plant to can recover up to $95 \%$ of $\mathrm{C} 4$ using mixed refrigerant type instead of pure propane refrigerant. Figure (10) is the Hysys simulation model for application of the mixed refrigerant.

The HYSYS model (Figure 10) had been built based on the same basis of design case in terms of feed flow rates, feed composition analysis, operating capacities of existing mechanical refrigeration unit and product spec, as discussed before.

The results of process equipment rating and debottlenecking are typed below.

\section{Process equipment rating}

\section{Glycol injection system}

Referring to Figure (11), which shows freezing points of Glycol-water aqueous solution, glycol-water solution will not freeze at retrofit case operating condition $\left(-30{ }^{\circ} \mathrm{C}\right)$ as $(60-80 \%$ by weight) glycol water solution lowers the freezing temperature below -47 ${ }^{\circ} \mathrm{C}$, as ethylene glycol disrupts hydrogen bonding when dissolved in water. A mixture of $60 \%$ ethylene glycol and $40 \%$ water freezes at $-45^{\circ} \mathrm{C}$ [9].

In refrigeration unit, as the temperature decreases, the glycol re-boiler duty increases slightly; as a result of slightly increase in condensed water (from $186.7 \mathrm{bbl} /$ day as per design model to 190.5 as per retrofitted model). So, There is no need to provide another dehydration process scheme or to relocate the molecular sieve dehydration unit, the existing glycol injection system will serve for the new deep cooling condition requiring adding minor heat duty for glycol reboiler.

\section{Mechanical Refrigeration Package}

The propane refrigeration facilities will serve for the retrofit as it will operate at design case capacities, and the circulated refrigerant mass rate will be at/or lower than the design case (760.8 ton/day). Propane gas chiller will be replaced by plate and fin heat Exchanger (MR Evaporator) with $13 \mathrm{MMBtu} / \mathrm{hr}$ heat duty, due to: 


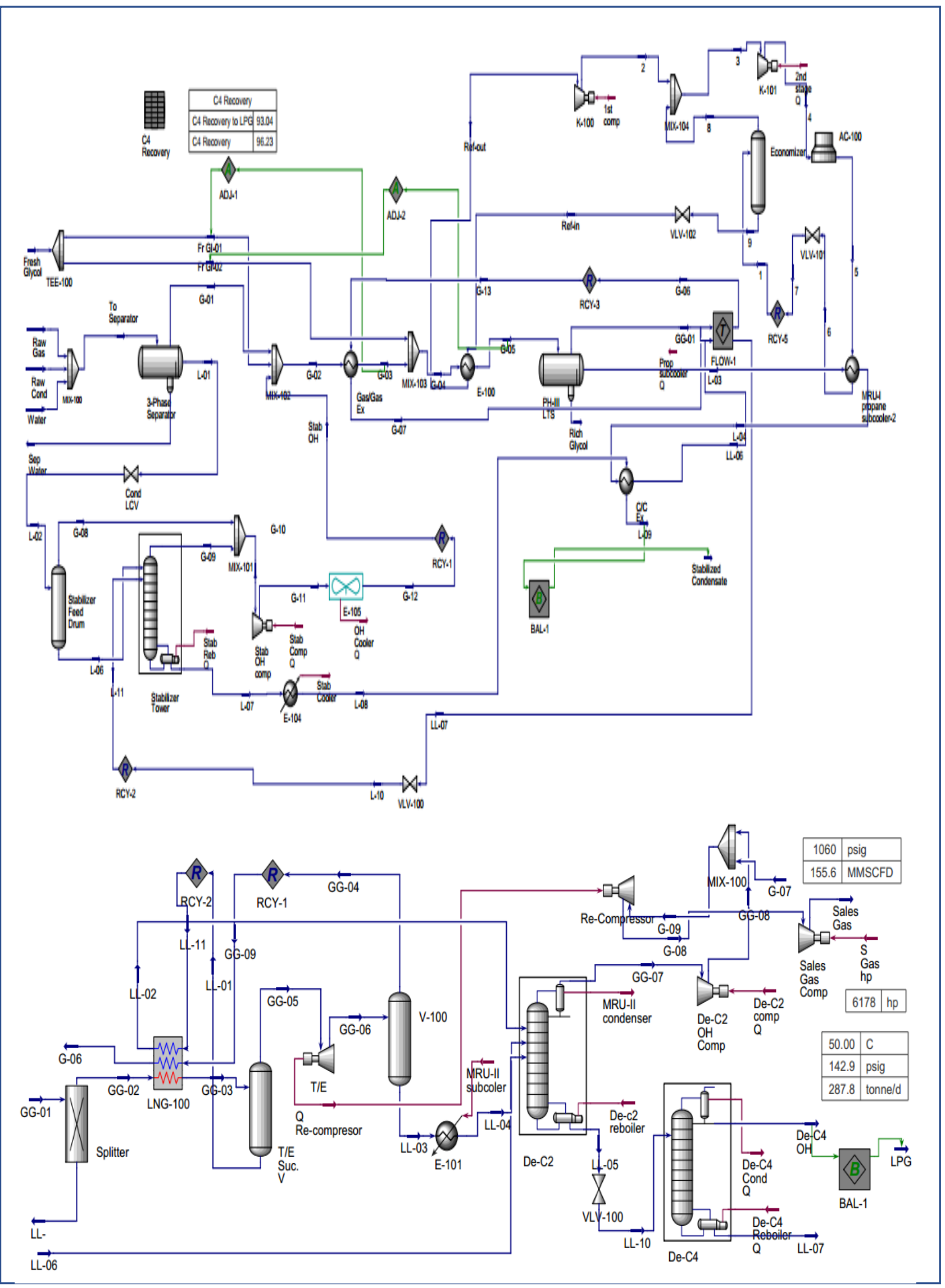

Figure 2 HYSYS flow sheet of Upgrading Mechanical refrigeration 


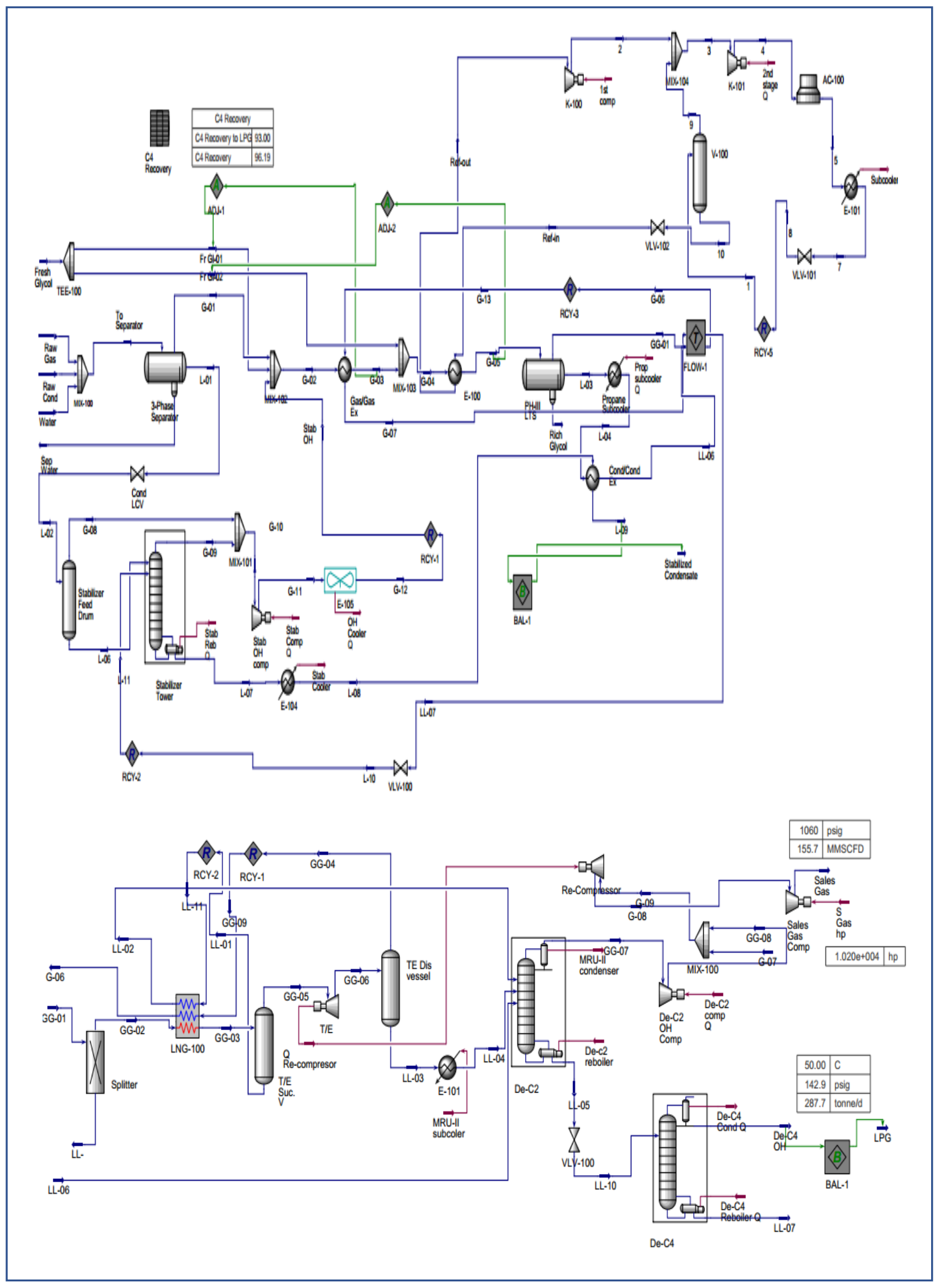

Figure 3 HYSYS flow sheet of Upgrading Turbo-Expander 


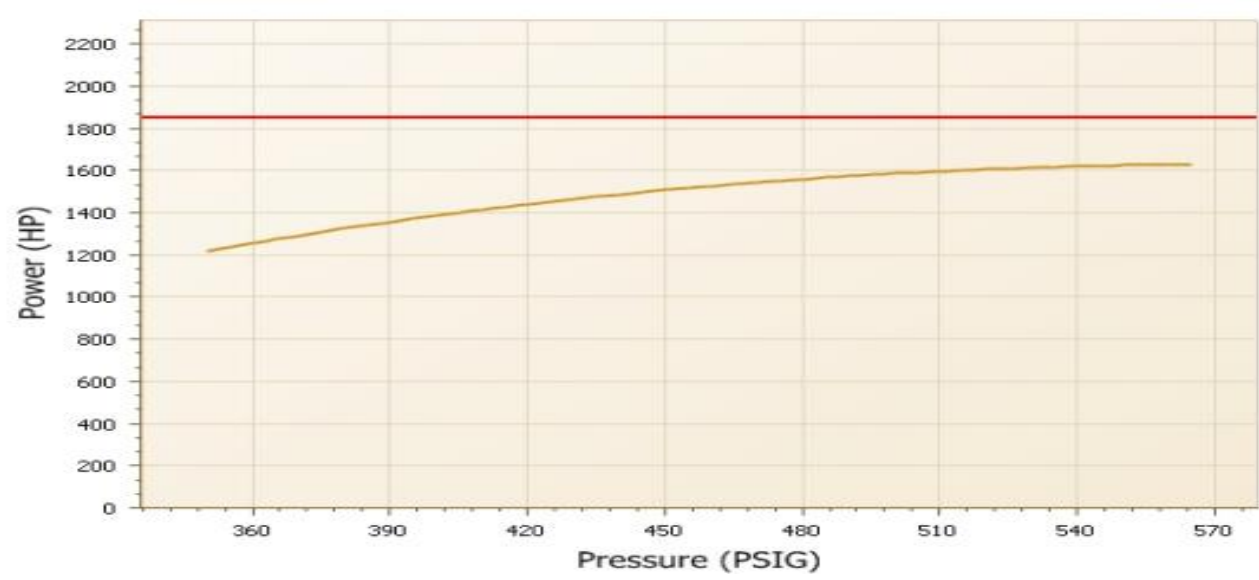

Figure 4 Dresser Rand performance curve (power Vs. Suction Pressure)

Table 2 the merits of mixed refrigerant cycles over pure refrigerant cycles

\begin{tabular}{|l|c|c|c|c|c|c|}
\hline & $\begin{array}{c}\text { Ex. Eff. } \\
\%\end{array}$ & $\begin{array}{c}\Delta \text { so comp. } \\
\text { BTU/lb }\end{array}$ & $\begin{array}{c}\Delta \text { s evaporation } \\
\text { BTU/lb }\end{array}$ & COP & UA \\
BTU/F hr & $\begin{array}{c}\text { Exergy loss } \\
\text { BTU/hr }\end{array}$ \\
\hline Pure propane & 29.22 & 1.10 & 9.32 & 0.75 & 1090231 & 515792 \\
\hline Mixed Refrigerant & 47.89 & 0.80 & 17.13 & 0.80 & 4700616 & 128543 \\
\hline
\end{tabular}

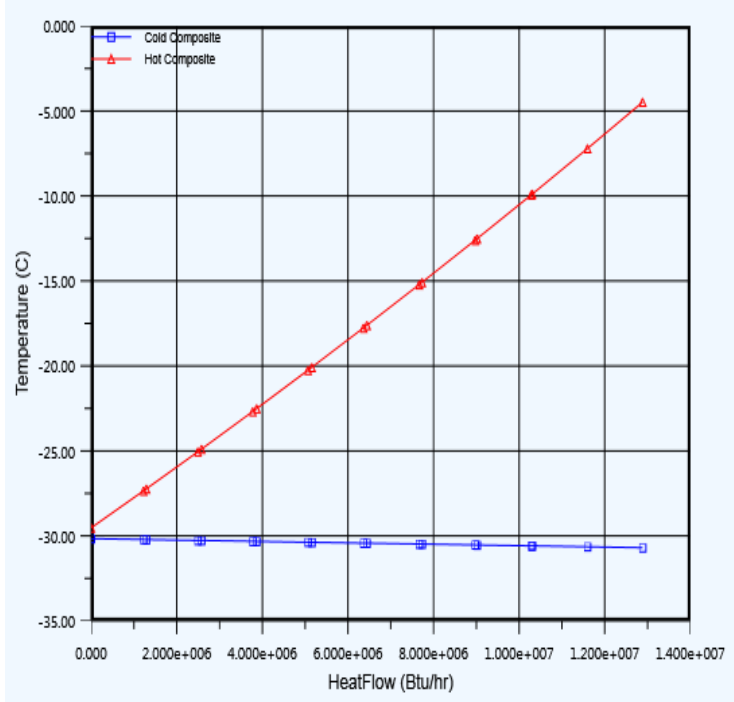

Figure 5 propane chiller heating/cooling curves

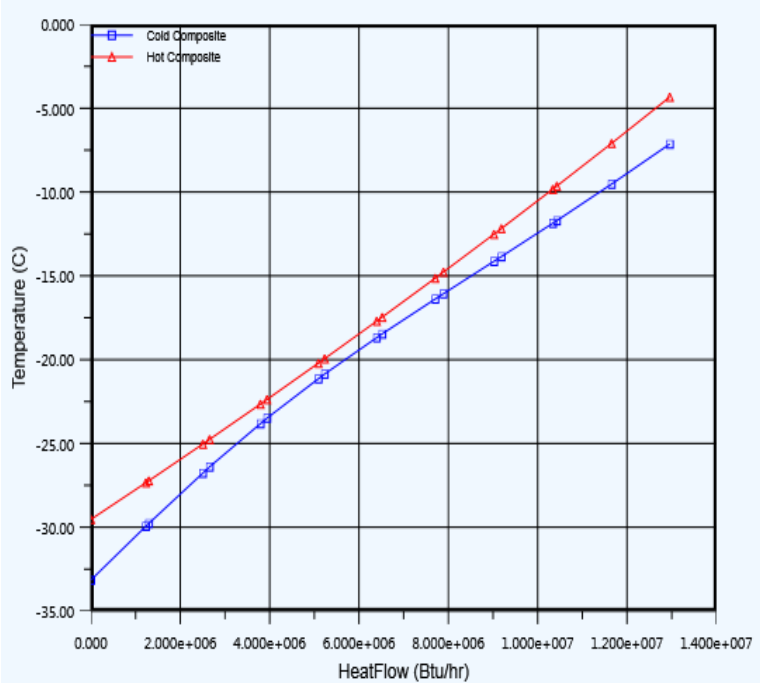

Figure 6 Mixed Refrigerant chiller heating/cooling

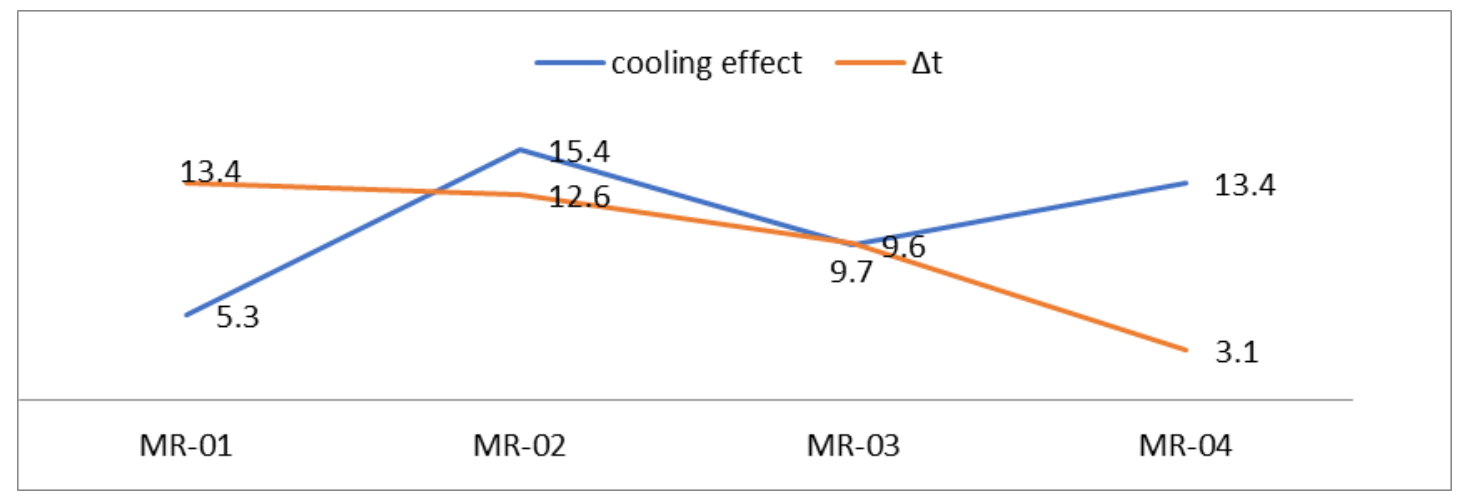

Figure 7 mixed refrigerant composition VS cooling effect \& $\Delta T$ 


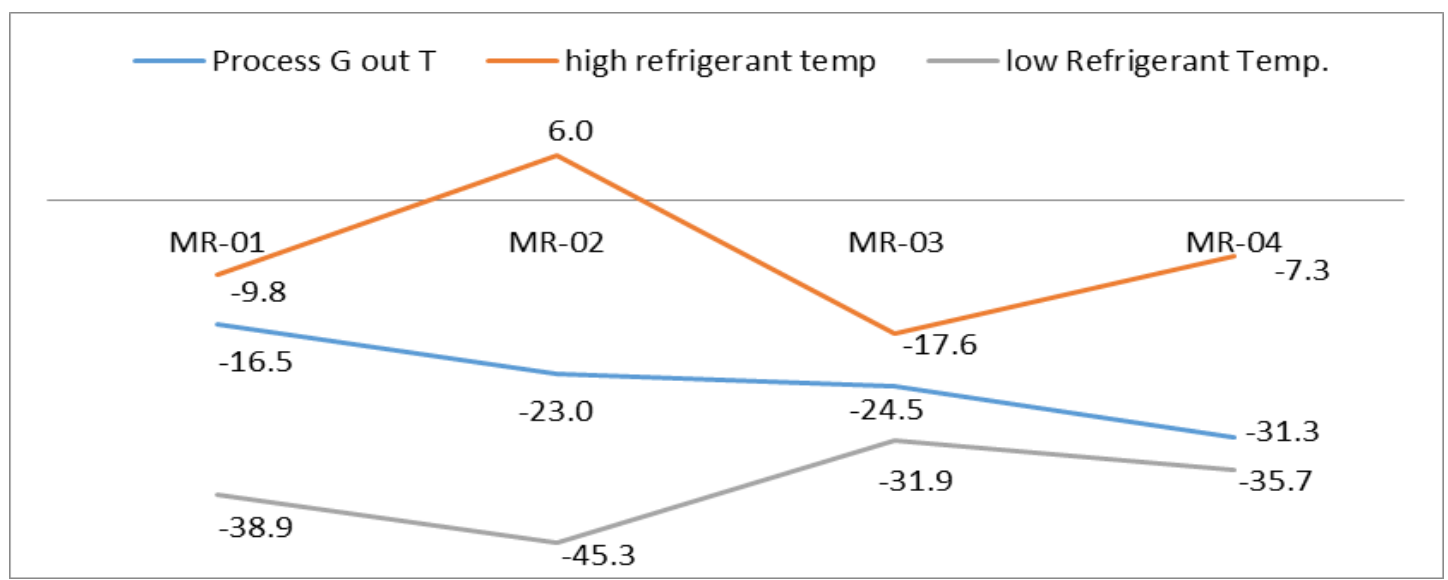

Figure 8 Mixed refrigerant composition VS streams Temperature

Table 3 Different mixed refrigerant composition

\begin{tabular}{|l|c|c|c|c|}
\hline Mass fraction & MR-01 [46] & MR-02[47] & MR-03 & MR-04 \\
\hline Methane & 0.14 & 0.00 & 0.00 & 0.00 \\
\hline Ethane & 0.23 & 0.18 & 0.25 & 0.198 \\
\hline Propane & 0.46 & 0.34 & 0.70 & 0.605 \\
\hline Iso-Butane & 0.06 & 0.24 & 0.02 & 0.091 \\
\hline N-Butane & 0.09 & 0.24 & 0.03 & 0.106 \\
\hline Iso-Pentane & 0.01 & 0.00 & 0.00 & 0.000 \\
\hline N-Pentane & 0.01 & 0.00 & 0.00 & 0.000 \\
\hline
\end{tabular}

Table 4 Different mixed refrigerant composition VS operating condition

\begin{tabular}{|l|l|l|l|l|}
\hline & MR-01 & MR-02 & MR-03 & MR-04 \\
\hline Cooling effect, MMBtu/hr & 5.3 & 15.4 & 9.6 & 13.4 \\
\hline$\Delta \mathbf{t},{ }^{\circ} \mathrm{C}$ & 13.4 & 12.6 & 9.7 & 3.1 \\
\hline Process gas outlet Temp. $(\mathbf{G}$ out $\mathbf{T})$, & -16.5 & -23.0 & -24.5 & -31.3 \\
\hline High refrigerant temp.,${ }^{\circ} \mathrm{C}$ & -9.8 & 6.0 & -17.6 & -7.3 \\
\hline Low refrigerant temp, ${ }^{\circ} \mathrm{C}$ & -38.9 & -45.3 & -31.9 & -35.7 \\
\hline Mass rate, ton/day & 573 & 797.2 & 730 & 747 \\
\hline
\end{tabular}

Table 5 total capital investment for the applicable techniques

\begin{tabular}{|l|c|c|c|c|}
\hline approach & $\begin{array}{c}\text { Fixed capital cost, } \\
\text { MM\$ }\end{array}$ & $\begin{array}{c}\text { Working capital } \\
\text { cost, MM\$ }\end{array}$ & $\begin{array}{c}\text { Operating cost, } \\
\text { MM\$/yr }\end{array}$ & $\begin{array}{c}\text { Total capital } \\
\text { investment MM\$/yr }\end{array}$ \\
\hline $\begin{array}{l}\text { Upgrading mechanical } \\
\text { refrigerant }\end{array}$ & 8.999 & 0.270 & 1.515 & 10.785 \\
\hline $\begin{array}{l}\text { Upgrading Turbo } \\
\text { Expansion }\end{array}$ & 7.344 & 0.220 & 2.471 & 10.036 \\
\hline Mixed Refrigerant & 3.140 & 0.094 & 0.553 & 3.787 \\
\hline
\end{tabular}




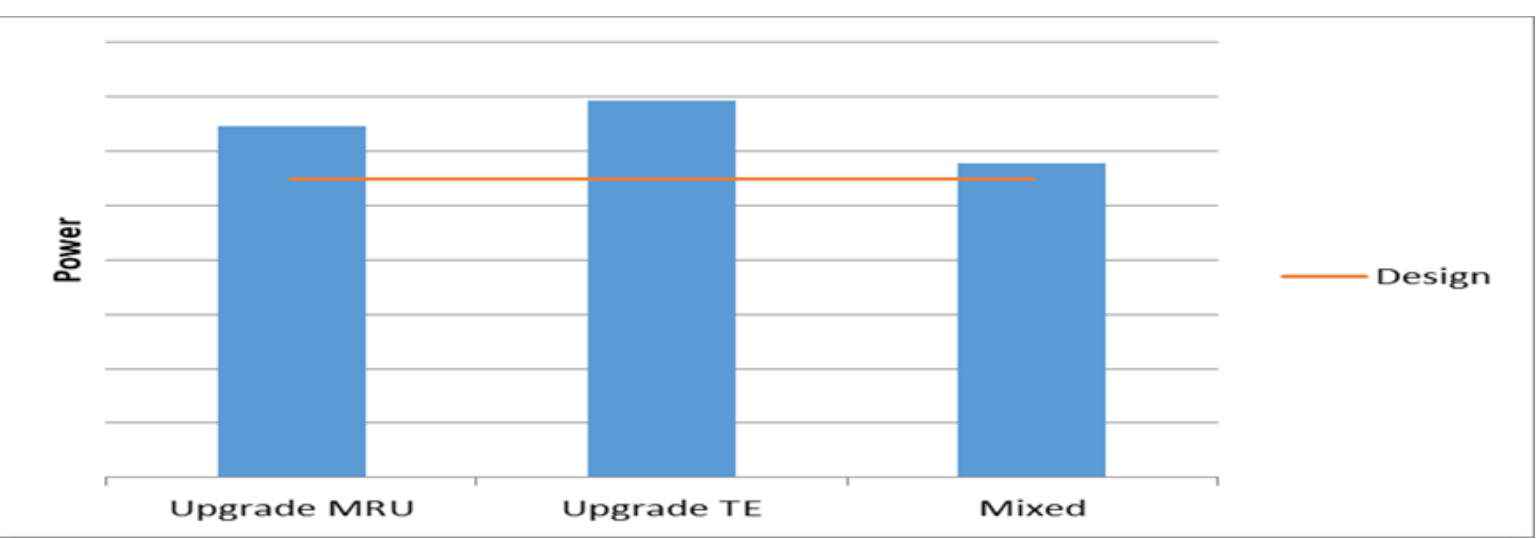

Figure 9 Total power consumed of upgrading approaches relative to design case

Table 6: Effect of PF MR Condenser on plant energy saving

\begin{tabular}{|l|c|c|}
\hline Parameter & PF MR & Dedicated MR \\
\hline TE discharge vessel liquid T, ${ }^{\circ} \mathrm{C}$ & -56.1 & -56.1 \\
\hline TE suction vessel liquid T, ${ }^{\circ} \mathrm{C}$ & -32.01 & -32.01 \\
\hline PH-III LTS liquid T, ${ }^{\circ} \mathrm{C}$ & -12.61 & -12.61 \\
\hline Tray\#4 feed T, ${ }^{\circ} \mathrm{C}$ & -7 & -56.1 \\
\hline Tray\#7 feed T, ${ }^{\circ} \mathrm{C}$ & 8 & -32.01 \\
\hline Tray\#10 feed T, ${ }^{\circ} \mathrm{C}$ & 20 & -12.61 \\
\hline Dedicated MR condenser, MMBtu/hr & - & 5.951 \\
\hline De-C2 Reboiler Duty, MMBtu/hr & 8.882 & 12.83 \\
\hline De-C2 Condenser Duty, MMBtu/hr & 3.108 & 1.357 \\
\hline Total duties required, MMBtu/hr & 11.99 & 20.138 \\
\hline Energy Saving duties, MMBtu/hr & \multicolumn{2}{|c|}{} \\
\hline Energy Saving percent & \multicolumn{2}{|c|}{40} \\
\hline
\end{tabular}

Table 7 MR Condenser effect on De-Ethanizer tower flooding analysis

\begin{tabular}{|l|c|c|c|c|}
\hline \multirow{2}{*}{ Parameter } & \multicolumn{2}{|l|}{ Using MR condenser } & \multicolumn{2}{l|}{ Without MR condenser } \\
\hline \multirow{2}{*}{$\begin{array}{l}\text { Tray\#4 feed, actual } \\
\text { volume bbl/day }\end{array}$} & Gas & Liquid & Gas & Liquid \\
\hline & 13247 & 771 & 2976 & 1970 \\
\hline $\begin{array}{l}\text { Tray\#4 feed, actual } \\
\text { volume bbl/day }\end{array}$ & 19645 & 1742 & 8959 & 3339 \\
\hline $\begin{array}{l}\text { Tray\#4 feed, actual } \\
\text { volume bbl/day }\end{array}$ & 8929 & 4674 & 7021 & 5233 \\
\hline DC back up \% & \multicolumn{2}{|c|}{$20-40 \%$} & $30-50 \%$ \\
\hline Flooding Percent & $40-65 \%$ & \multicolumn{2}{c|}{$60-90 \%$} \\
\hline
\end{tabular}




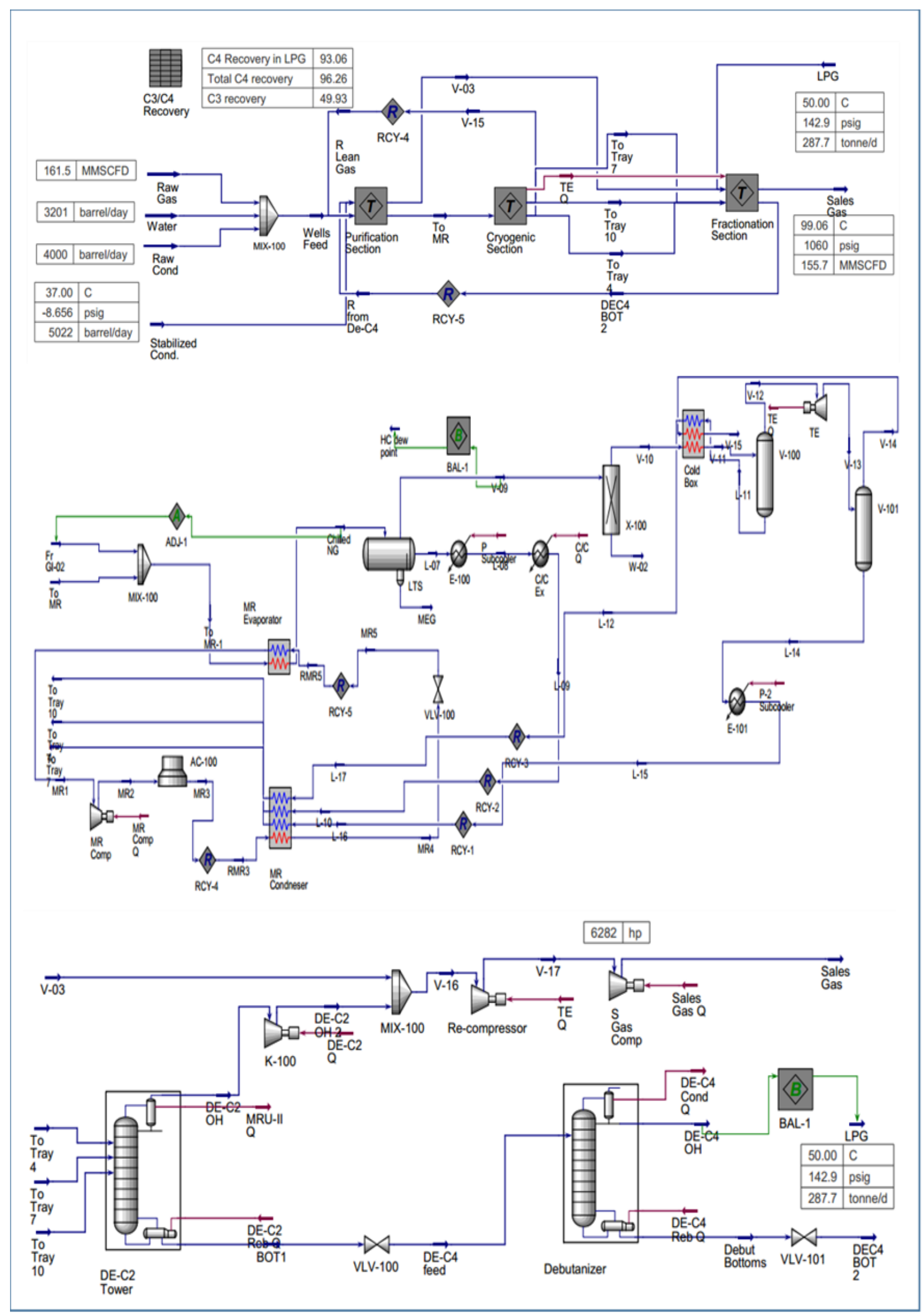

Figure 10 HYSYS flow sheet of LPG recovery mode 


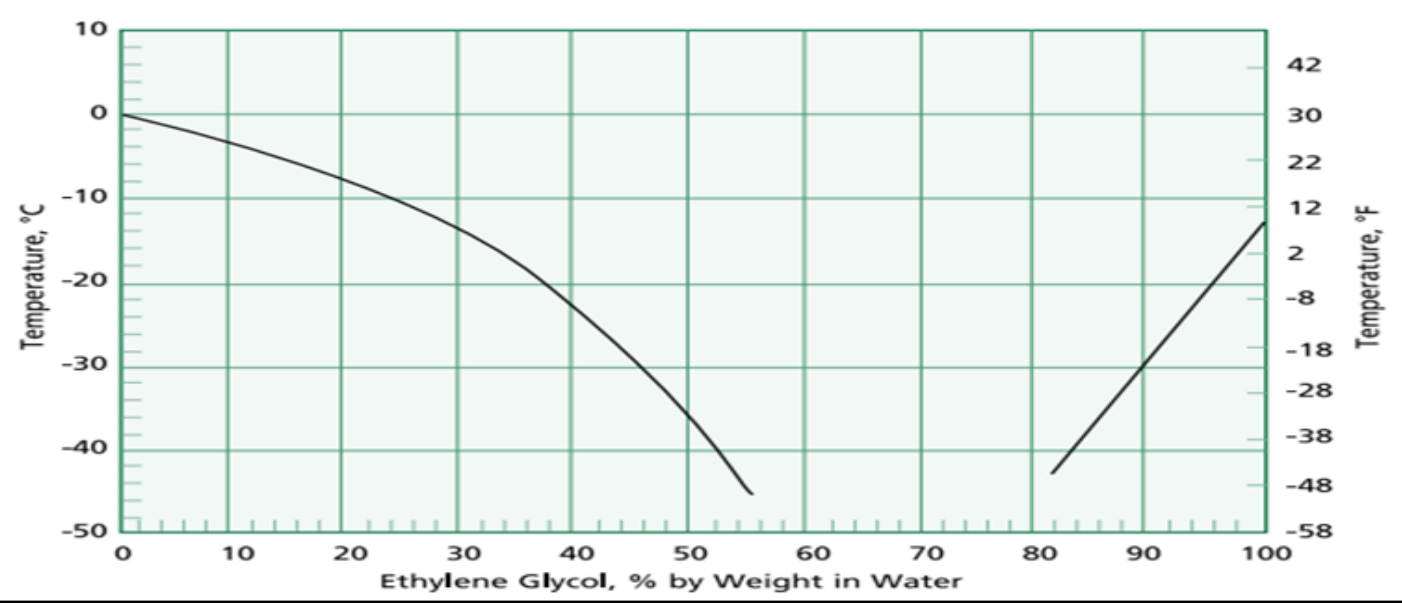

Figure 11 Freezing Points of Aqueous Ethylene Glycol Solutions [10]

Table 8 gained revenue from original and retrofitted cases

\begin{tabular}{|l|c|c|}
\hline Parameter & Design & Retrofitted \\
\hline Sales Gas, MMSCFD & 156.4 & 155.7 \\
\hline LPG, ton/day & 228.4 & 287.7 \\
\hline Condensate, bbl/day & 4999 & 5022 \\
\hline heating Value, Btu/scf & 1088 & 1081 \\
\hline Annual Gas Revenue, MM\$ & 245.03 & 242.36 \\
\hline Annual LPG Revenue, MM\$ & 65.77 & 82.85 \\
\hline Annual Condensate Revenue, & 161.96 & 162.71 \\
\hline Total Revenue, MM\$ & 472.78 & 487.93 \\
\hline incremental revenue, MM\$ & & 15.15 \\
\hline
\end{tabular}

Table 9 Economic study results for LPG recovery mode

\begin{tabular}{|l|c|}
\hline Item & Cost \\
\hline Fixed Capital Investment & 3.140 \\
\hline working capital cost (MM\$) & 0.094 \\
\hline Operating Cost (MM\$) & 0.553 \\
\hline Total Capital Investment & 3.787 \\
\hline incremental revenue (MM\$) & 15.15 \\
\hline ROI (return on investment) (\%) & 400.24 \\
\hline Pay-Back Time (Months) & 3 \\
\hline
\end{tabular}

Table 10 Case study 2 mixed refrigerant composition for propane recovery mode

\begin{tabular}{|l|l|l|l|l|}
\hline Mass fraction & MR-01[46] & MR-02[47] & MR-05 & MR-06 \\
\hline Methane & 0.14 & 0.00 & 0.00 & 0.00 \\
\hline Ethane & 0.23 & 0.18 & 0.35 & 0.365 \\
\hline Propane & 0.46 & 0.34 & 0.62 & 0.445 \\
\hline Iso-Butane & 0.06 & 0.24 & 0.01 & 0.09 \\
\hline N-Butane & 0.09 & 0.24 & 0.02 & 0.1 \\
\hline Iso-Pentane & 0.01 & 0.00 & 0.00 & 0.00 \\
\hline N-Pentane & 0.01 & 0.00 & 0.00 & 0.00 \\
\hline
\end{tabular}


Available Heat transfer surface area can't achieve the required chilling duty.

Default kettle type chiller require refrigerant level control to achieve proper heat transfer for whole tube surface area, lighter component will easily evaporate and portion of heavier component will concentrate in the chiller.

Plate and fin heat exchanger doesn't require level controlling; refrigerant is totally vaporized across the exchanger.

Plate and fin heat exchanger provide very close temperature approaches between the respective process streams.

Table (6) illustrate the effect of adding PF MR Condenser on plant energy saving.

\section{De-Ethanizer unit facilities}

As a result of retrofit modification and increasing degree of cooling, De-Ethanizer unit need to treat higher feed figures than that required by original design case, so each facility had been rated using HYSYS equipment design/rating tool and found:

Tray\#4 actual feed flow: 14019 bbl/day

Tray\#7 actual feed flow: 21387 bbl/day

Tray\#10 actual feed flow: $13603 \mathrm{bbl} /$ day

In case of feeding De-Ethanizer tower with the condensed streams of the original design arrangement, De-Ethanizer tower tend to cause flooding across trays, due to increasing liquid load. However, by using MR condenser, condensed streams will be heated before feeding to the tower to a degree that liquid load on trays decreased and flooding will not be occurred, Table (7) tabulates MR Condenser effect on De-Ethanizer tower flooding analysis.

De-Ethanizer reboiler had been rated to original design data sheet and according to retrofit operating condition, found that it provide the system with the required heat duty (8.883 $\mathrm{MMBtu} / \mathrm{hr}$ ) but by adding operating cost $(44,000 \$ / \mathrm{yr})$.

De-Ethanizer overhead condenser had been rated to original design data sheet and according to retrofit operating condition, found that it provide the system with the required heat duty ( $3.108 \mathrm{MMBtu} / \mathrm{hr}$ ) but by adding operating cost $(351,000 \$ / \mathrm{yr})$.

\section{Total Capital Investment}

Total revenue gained from both design and retrofitted case had been calculated based on pricing data given below as per Egyptian local market, 2013 and results are tabulated in Table (8).

\section{BTU of Gas $=4 \$$}

$\mathrm{BBL}$ of condensate $=90 \$$

Ton of $L P G=800 \$$

Total required capital investment had been calculated, depending on the purchased equipment prices [6] and Nelson Farrar cost index for 2006 \& 2016, results are tabulated in Table (9)
Mixed refrigerant selection for propane retrofitted plant

To select the optimum composition, which achieves the highest cooling effect, minimum temperature approach $\Delta T$ and the aimed cooling temperature to recover above $90 \%$ of propane at the same consumed power, results were tabulated in Table (10) and MR-06 was selected as the composition base for Propane recovery mode.

As shown from Figure (12) and Table (11), MR-02

\& MR-06 can achieve the highest cooling effect

Although MR-02 can achieve the highest cooling effect, but it exhibit a cross temperature heat

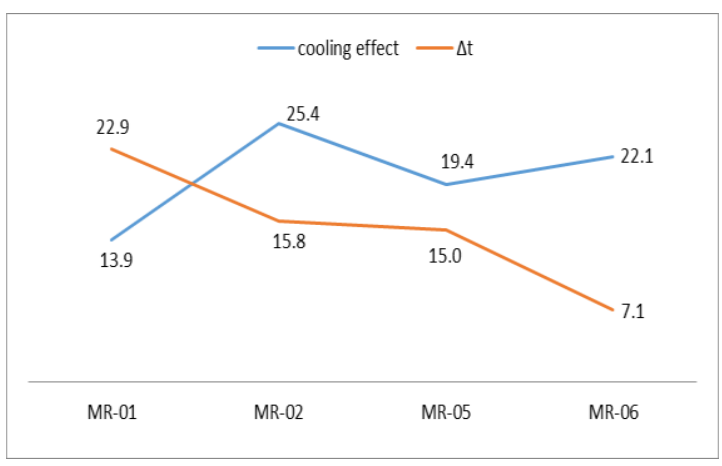

Figure 12 mixed refrigerant composition VS cooling effect $\& \Delta T$

exchanger, as the high refrigerant temperature is higher than the process gas in temperature $\left(5.7^{\circ} \mathrm{C}\right)$, so it can't be used for refrigeration as illustrated in Figure (13).

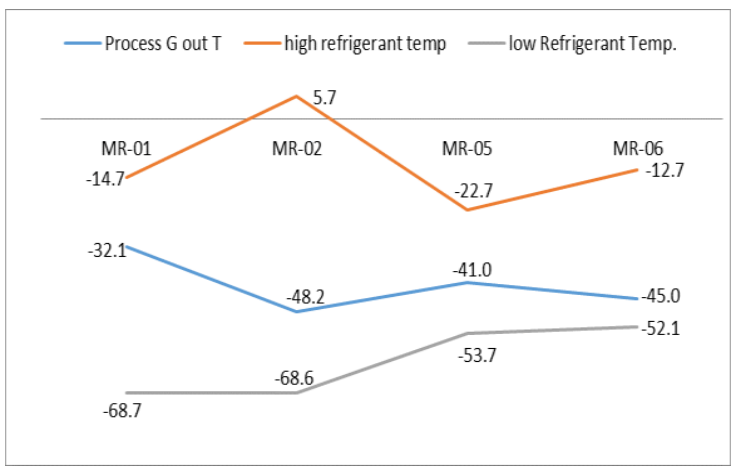

Figure 13 Mixed refrigerant composition VS streams Temperature

MR-06 is selected as a base composition for propane recovery mode.

The HYSYS model (Figure 14) had been built based on the same basis of design case in terms of feed flow rates, feed composition analysis. In addition to that, the propane recovery mode is limited to propane recovery up to $93 \%$ and propane product spec, as discussed before using mixed refrigerant. The results of Process Equipment rating and debottlenecking are typed below.

Process Equipment rating 
Table (12) listed the new required equipment which will achieve the required degree of cooling and propane recovery percent; meanwhile at design capacities it can't fit the new requirements.

\section{Glycol Injection system}

The effect of deep cooling to recover propane is the same for that of LPG recovery, except that heat duty consumed and circulated glycol rate is slightly high. In addition the behavior of glycol in low temperature service is as described above.

\section{Mechanical Refrigeration Package}

Propane gas chiller will be replaced by plate and fin heat Exchanger (MR Evaporator) with 22.07 $\mathrm{MMBtu} / \mathrm{hr}$ heat duty, due to the same reason listed above.

Meanwhile mixed refrigerant (MR-06) can't be condensed at design operating pressure and ambient temperature, and the condensed streams from MRU \& TE units have lower operating temperature than that of design case as a result of deep cooling which require higher heat duties at fractionation sections to meet product spec, Another Plate and fin heat exchanger (MR condenser) will be added to totally condense the mixed refrigerant by heating the cold condensed streams.

\section{Hot oil heating systems}

The total heat duties required for Stabilizer, DeEthanizer, De-Propanizer, De-Butanizer and Glycol reboilers by retrofit will be $33.791 \mathrm{MMBtu} / \mathrm{hr}$, which is slightly above the maximum design hot oil heater duty (32 MMBtu/hr), so additional hot oil heater is required to can accommodate the additional required heat duty and hence require additional capital cost (1.114251 MM\$) as described in Table (12).

\section{De-Ethanizer unit facilities}

As a result of retrofit modification and increasing degree of cooling, De-Ethanizer unit need to treat higher feed figures than that required by original design case, so each facility had been rated using HYSYS equipment design/rating tool and found it can't accommodate the new requirements due to flooding problem inefficient separation, and hence a new unit with all facilities will be required.

\section{De-Propanizer unit facilities}

As there was no propane recovery as per design case, it is required to add de-propanizer $\left(\mathrm{De}-\mathrm{C}_{3}\right)$ unit to can get on spec sales propane, meanwhile the original De- $C_{2}$ unit will be replaced by a high capacity one and the De- $\mathrm{C}_{2}$ feed load is close to that of original De- $C_{2}$ feeed load, it will be used to serve as De- $C_{3}$ unit.

\section{Sales gas compression station}

Sales gas compression station depend mainly on expansion degree at turbo expander (encountered $\Delta \mathrm{P}$ ), which is constant for both cases (design and retrofit), and as a result of deep cooling a great portion of propane will be excluded from sales gas to be fed to fractionation towers, and hence the sales gas figures will be decreased and the required sales gas compression power will be decreased to $4201.82 \mathrm{hp}$.
Propane storage facilities

It is required to install storage facilities for sales propane based on the same storage philosophy of LPG; one in production service, another one in dispatching service and the last one is stand-by, so the capacity of each one is estimated by 250 ton of stored propane.

\section{Total Capital Investment}

Total revenue gained from both design and retrofitted case had been calculated based on pricing data given below as per Egyptian local market 2013, and results are tabulated in Table (13).

MM BTU of Gas $=4 \$$

$\mathrm{BBL}$ of condensate $=90 \$$

Ton of LPG $=800 \$$

Ton of sales Propane $=900 \$$

Total required capital investment had been calculated, depending on the purchased equipment prices and Nelson Farrar cost index for 2006 \& 2016, results are tabulated in Table (14).

\section{Conclusions and Recommendations}

NGL and LPG plants in operation require continuous innovation and adaptation in process technologies and suitable selection of operating condition in order to increase their revenues. It is found that mixed refrigerant is favored for some cryogenic units than pure refrigerant, due to its proper thermodynamic and physical properties for heat transfer that can raise exchanger effectiveness \& C.O.P and reduce exergy loss.

Mixed refrigerant evaporates at a wide range of evaporating temperature, this could keep minimum temperature approach across the chilling process and led to closure of chilling curves, subsequently better heat transfer; over all plant power consumption could be decreased as a result of the mentioned merits of mixed refrigerant. Proper mixed refrigerant composition is selected, to save consumed power and total capital cost.

Retrofit the existing plant by upgrading mechanical refrigeration unit will require the highest capital investment among the provided approaches for NGL recovery.

Retrofit the existing plant by upgrading Turboexpansion unit will require the highest operating cost among the provided techniques for NGL recovery. Mixed refrigerant technique exhibit the lowest operating and capital cost among the provided techniques for NGL recovery. Energy saving was considered, by utilizing the extra cooled streams for cooling the feed and condensing the refrigerant. 
Table 11 Different mixed refrigerant composition VS operating condition

\begin{tabular}{|l|l|l|l|l|}
\hline & MR-01 & MR-02 & MR-05 & MR-06 \\
\hline cooling effect, $\mathrm{MMBtu} / \mathrm{hr}$ & 13.9 & 25.4 & 19.4 & 22.1 \\
\hline$\Delta \mathbf{t},{ }^{\circ} \mathrm{C}$ & 22.9 & 15.8 & 15.0 & 7.1 \\
\hline Process G out $\mathbf{T},{ }^{\circ} \mathrm{C}$ & -32.1 & -48.2 & -41.0 & -45.0 \\
\hline high refrigerant temp, $^{\circ} \mathrm{C}$ & -14.7 & 5.7 & -22.7 & -12.7 \\
\hline low refrigerant temp, $^{\circ} \mathrm{C}$ & -68.7 & -68.6 & -53.7 & -52.1 \\
\hline mass rate, ton/day $^{\text {Power, hp }}$ & 835 & 1149.0 & 1027 & 1150 \\
\hline
\end{tabular}

Table 12 List of new required equipment

\begin{tabular}{|c|c|c|c|c|c|c|}
\hline \multirow[t]{2}{*}{ New Equipment } & \multirow[t]{2}{*}{ Parameter / unit } & \multirow[t]{2}{*}{ Design case } & \multirow{2}{*}{$\begin{array}{l}\text { Retrofitted } \\
\text { Case }\end{array}$} & \multicolumn{2}{|c|}{ Additional } & \multirow{2}{*}{$\begin{array}{l}\text { Unit Cost, } \\
\text { MM\$ }\end{array}$} \\
\hline & & & & Power & $\begin{array}{l}\text { Cost, } \\
\mathrm{MM} \$ / \mathrm{yr}\end{array}$ & \\
\hline Gas Chiller PF & Heat duty, MMBtu/hr & - & 22.07 & - & - & 2.656693 \\
\hline MR Condenser & Heat duty, MMBtu/hr & - & 8.564 & - & - & 1.505449 \\
\hline MR compressor & Heat duty, MMBtu/hr & - & 2081 & 2081 & 1.067 & 2.467160 \\
\hline MR pre cooler & Heat duty, MMBtu/hr & - & 14.60 & 14.60 & 0.122 & 1.545000 \\
\hline De-C2 Reboiler & Heat duty, MMBtu/hr & 8.378 & 14.34 & 5.962 & 0.515 & 0.352863 \\
\hline De-C2 Cond. & Heat duty, MMBtu/hr & 1.366 & 7.47 & 6.104 & 0.527 & 6.706873 \\
\hline De-C2 OH Comp & $\mathrm{Hp}$ & 94.97 & 249 & 170.03 & 0.079 & 1.989596 \\
\hline De-C2 tower & Actual volume flow, & 20198 & 77700 & - & & 2.311607 \\
\hline De-C3 OH EX & Heat duty, MMBtu/hr & - & 3.073 & - & - & 0.172918 \\
\hline HM furnace * & Heat duty, MMBtu/hr & - & - & - & - & 1.114251 \\
\hline Propane bullets & Ton & - & - & - & - & 5.980046 \\
\hline
\end{tabular}

*The required additional power/cost had been already included for each reboiler separately

Table 13 Gained revenue from original and retrofitted cases

\begin{tabular}{|l|c|c|}
\hline Parameter & Design & Retrofitted \\
\hline Sales Gas, MMSCFD & 156.4 & 153.7 \\
\hline LPG, ton/day & 228.4 & 260.1 \\
\hline Propane, ton/day & - & 137.1 \\
\hline Condensate, bbl/day & 4999 & 5043 \\
\hline heating Value, Btu/scf & 1088 & 1035 \\
\hline Annual Gas Revenue, MM\$ & 245.03 & 229.074 \\
\hline Annual LPG Revenue, MM\$ & 65.77 & 74.908 \\
\hline Annual Propane Revenue, MM\$ & - & 44.420 \\
\hline Annual Condensate Revenue, MM\$ & 161.96 & 163.393 \\
\hline Total Revenue, MM\$ & 472.78 & 511.796 \\
\hline incremental revenue, MM\$ & & 39.015 \\
\hline
\end{tabular}

Table 4 Economic study results for propane recovery mode

\begin{tabular}{|l|r|r|}
\hline Fixed Capital Investment & 26.802 & MM\$ \\
\hline working capital cost & 0.804 & MM\$ \\
\hline Operating Cost & 2.838 & MM\$ \\
\hline Total Capital Investment & 30.444 & MM\$ \\
\hline incremental revenue & 39.015 & MM\$ \\
\hline ROI (return on & 128.15 & $\%$ \\
\hline Pay-Back Time & 9.36 & Months \\
\hline
\end{tabular}




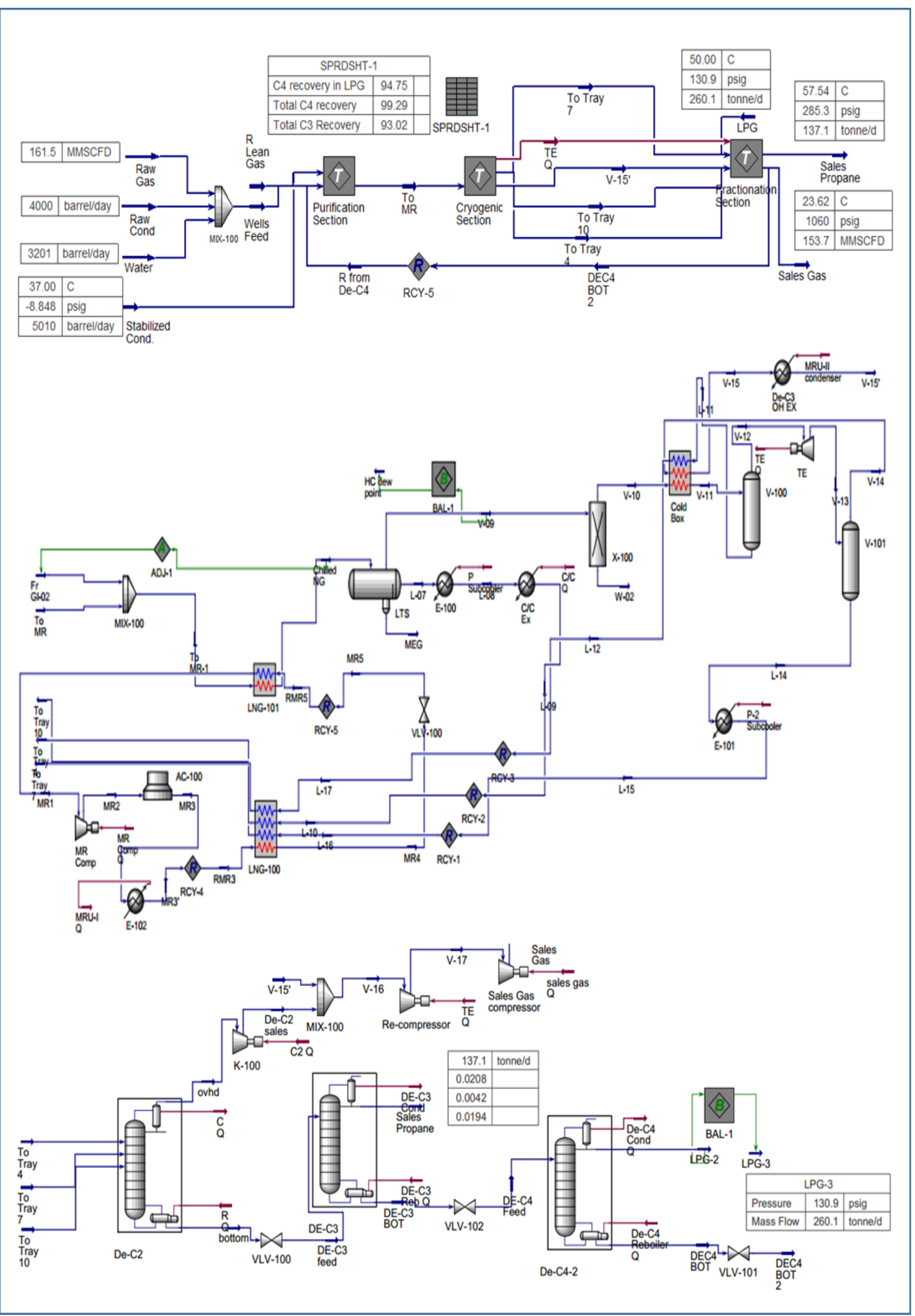

Figure 14 HYSYS flow sheet of Propane recovery mode 
De-Ethanizer operating conditions were revisited to enhance unit reliability and availability and to save additional required capital cost. Retrofitting the existing plant to can recover above $95 \%$ of LPG can achieve the highest ROI and lowest Pay-Back period than propane recovery mode. Retrofitting the existing plant to can recover above $93 \%$ of propane can raise productivity and profitability more than LPG recovery mode. The study can be used in conceptual engineering and in contractor/ licensor evaluations. Hence, we recommend getting advantage of this work for further study to increase the productivity and profitability of the existing LPG plant or any other units recover NGL, to enhance the feed stock to the petrochemical industries.

\section{REFERENCES}

[1] http://www.bentekenergy.com/NGL.aspx

[2] Mokhatab, S., Poe, W. A., Speight, J. G. handbook of natural gas transmission and processing, Elsevier, 2006.

[3] Presson-Enerflex, "El-Wastani petroleum company operation and maintenance commissioning protocol”, Egypt, 2006.

[4] Alfeev, V. N., Brodyanskii, V., Yagodin, V., Nikolsky, V., Ivantsov, A Refrigerant for a cryogenic throttling unit, U.K. Patent 1,336,892 (1973).

[5] Khabibullin, E., Febrianti, F., Sheng, J., and Bandyopadhyay, S., Process Design and Economic Investigation of LPG Production from Natural Gas Liquids (NGL), NTNU, TKP 4170 Process design. Project, 2010

[6] Peters S., Klaus, D. Timmerhaus, Plant Design and Economics for Chemical Engineers, Fourth Edition McGraw-Hill, Inc. 1991

[7] Mackenzie, D.H., Donelly, S.T., Mixed Refrigerants proven efficient in natural gas liquid recovery process, 1985 edition of oil and gas journal.

[8] Rowles et al., Mixed Refrigerant/Expander process for recovery of $\mathrm{C} 3+$ Hydrocarbons, patent no. 4921514.

[9] Weinheim: Wiley-VCH, Siegfried Rebsdat, Ethylene Glycol, Ullmann's Encyclopedia of Industrial Chemistry, Dieter Mayer (2005).

[10] 10-Cordray, D.R., Kaplan, L.R., Woyciesjes, P.M. and Kozak, T.F., Solid-Liquid Phase Diagram for Ethylene Glycol + Water, Fluid Phase Equilibria117, pp. 146-152 (1996).

[11] Abdel-Aal, H. K., Aggour, M., Fahim, M. A. Petroleum and Gas Field Processing Marcel Dekker, New York, USA, 2003.

[12] Joe T. L., John D. W., Hank M. H., Richard N. P. Process retrofits maximize the value of existing NGL and LPG recovery plants, Ortloff Engineers, Ltd. 2003, Midland, Texas. 